\title{
The Concept of Luxury Brands and the Relationship between Consumer and Luxury Brands*
}

\author{
Kip Becker ${ }^{1}$, Jung Wan Lee ${ }^{2}$, Helena M. Nobre ${ }^{3}$ \\ Received: May 30, 2018 Revised: July 17, 2018 Accepted: July 30, 2018
}

\begin{abstract}
The study aims to articulate a definition of luxury brands, to propose a framework for consumer luxury brand relationships and to provide empirical evidence of the proposed model. The study conducted two surveys in Portugal and the United States in 2009 and 2013 for selected luxury brands. The study employs factor analysis and structural equation modelling techniques to test the hypotheses. The study finds a link between luxury products and consumer's psychological association represents in a hierarchical order of: cognitive attributes at its base level, extrinsic attributes on a secondary level and intrinsic attributes at the advance level. The findings suggest a concept for luxury brands from three dimensions of: luxury product characteristics, consumer's psychological characteristics, and consumer's psychological association with the luxury product. The research was conducted in Portugal and the United States so that there is always a potential criticism concerning the ability to generalize research results to a broader international population. The findings provide a holistic perspective in the understanding of luxury brand constructs and a definition of luxury brands in the way why consumers involve symbolic consumption. The successful application of the findings in a brand setting would be of particular interest to marketers and brand strategists.
\end{abstract}

Keywords: Luxury Brand, Luxury Product, Brand Personality, Consumer Behavior, Brand Strategy.

JEL Classification Code: M11, M31, M37.

\section{Introduction}

A luxury brand represents specific social and cultural meanings conveyed by the product or brand that are used by consumers. It describes their personal and social

* The paper with the title ["A Predictive Model of Consumer-Luxury Brand Relationships"] was presented initially at the 9th Annual Conference of the EuroMed Academy of Business (EMAB2016) that was held in Warsaw, Poland, September 14-16, 2016. This paper is a substantially revised and expanded version of the paper presented at EMAB2016 conference. The authors have taken into account all the comments of Editors, Session Chairs and Reviewers in the revised manuscript. The authors greatly appreciate Editors, Session Chairs and Reviewers for their valuable comments, interest in and support of this research.

1 First Author. Associate Professor Emeritus, Administrative Sciences Department, Metropolitan College, Boston University, Boston, USA Email: kbecker@bu.edu

2 Corresponding Author. Assistant Professor, Administrative Sciences Department, Metropolitan College, Boston University [Postal Address: 808 Commonwealth Avenue, Boston, MA 02215, USA] Email: jwlee119@bu.edu

3 Assistant Professor, DEGEIT - Economics, Management, Industrial Engineering and Tourism, GOVCOPP, University of Aveiro, Aveiro, Portugal E-mail: hnobre2@gmail.com relationship with the brand and their position with others in society. Over the last two decades, the luxury construct has gained relevance in the literature due to the creation of conglomerates such as Moët Hennessy Louis Vuitton or LVMH, Gucci Group and Richemont SA (Okonkwo, 2009). Luxury brands have also achieved a level of economic importance due to their elevated status in contemporary consumption and communication activities (Chevalier \& Manzalovo, 2008). Throughout the recent economic downturn, the revenue and profit margins of the luxury goods market remained relatively solid. The 2013 recognition by the European Commission that acknowledged the luxury goods market as a sector in its own right rather than a part of another industry provides leadership relating to the prominence of the product group (Daneshkhu, 2013).

Reyneke et al. (2012) highlight this issue investigating the relationship between the performance of luxury brands and the economic cycle, specifically the effect that recessions have on luxury brands. Riley et al. (2004) comment that the marketing function rather than the research and development has the strongest influence on brand extension in the luxury sector, and therefore the brand heritage identified by luxury goods experts is considered as an important decision criterion for brand extensions. While 
there has been increasing research relating to luxury brands, there is no clear, consistent, or agreed upon definition of what constitutes the core elements of a luxury brand. Without a better, consistent and accepted definition, there is likely to be inconsistency in future research outcomes as a result of investigations examining different categories of products. It is highly probable that there will be economic issues (e.g. luxury tax), trade issues (e.g. tariffs) and cultural confusions. As investigations into products classified as luxury brands escalate, it will also be increasingly difficult to compare research results. This oversight provides further credence to the authors' belief that an agreement of what constitutes a luxury product or brand is vital to assure that there is a broadly accepted meaning resulting in a standardized use of the term.

Recognition of the importance of brand relationships, such as how they are established and factors that might influence the link during situations of brand disruption, is also of increasing importance. Becker and Nobre (2013) find that loyalty bonds serve to maintain the relationship through developed proxy quality, while intimacy bonds were to a much lesser extent associated with relationship strength. One might argue that in a brand loyalty relationship the brand adds value to the consumer through proxy quality in a manner similar to the way that loyalty adds value to the personal relationship. Given the differences in wealth and social class that exist among societies, consumers might aspire to luxury products for a number of reasons. As such the study of consumer luxury brand relationships is an attempt to understand the meanings that consumers bring to their lives when involved in social relationships with luxury brands.

The purposes of this research are: 1) to articulate a definition of luxury brands, 2) to propose a research framework for consumer luxury brand relationships and 3) to provide empirical evidence of the proposed model. The results of this study can help: 1) assure that those involved in luxury brand research are investigating the same types of products, 2) stimulate further empirical research on the consumer luxury brand relationship and 3) allow marketers to formulate better marketing strategies and managerial actions.

\section{Literature Review}

\subsection{The Concept of Luxury Brands}

Given the symbolic nature of luxury as well as the social and cultural meaning involved in luxury brands and product consumption a consumer-brand relationship based on the theories of social psychology appears as a rich depository of research. It was widely discussed that the way consumers perceive their experiences with products or brands gives meaning to their lives. Al-Mutawa (2013) proposes a definition of luxury fashion brands in terms of specific consumer group oriented representations. Wiedmann et al. (2009) discuss consumers' luxury value perceptions in terms of social, individual, functional and financial orientation consumer motives. Sung et al. (2015) propose a conceptual framework for luxury brand personality in terms of utilitarian benefits and symbolic meanings that luxury brands offer. Lee et al. (2015) also propose a conceptual framework for luxury disposition behavior in terms of luxury customer values, financial and relational aspects. Lee (2013) also proposes a conceptual framework for luxury brand personality in terms of psychological and sociocultural aspects. Wong and Ahuvia (1998) discuss cultural issues associated with luxury consumption in terms of the link between materialism and conspicuous consumption. Liao and Wang (2009) also discuss how the relationship between materialism and brand consciousness reciprocates.

There is some agreement in the literature that a luxury brand represents social and cultural meanings that are used by consumers to fulfill their social goals (Wilcox et al., 2009). These social goals may be of social adjustment order, value expressive order or a mix of both. A luxury brand carries out important symbolic meaning that fulfills consumers' psychological needs. This leads to an emphasis on psychological benefits versus functional benefits as one of the features that characterizes luxury brands distinguishing them from non-luxury brands (Vigneron \& Johnson 2004). As such the study of luxury brands is an attempt to understand the meanings that consumers bring to their lives when involved in relationships with luxury brands. Ko and Megehee (2012) provide insight into the broad scope of luxury brand issues through describing several categories including: luxury values, luxury consumer behavior, luxury brand management and luxury brand counterfeiting.

Miller and Mills (2012) propose that it is difficult to move forward when current luxury brand theory resembles a patchwork of definitions, methods and metrics. Their research attempted to delineate luxury brands from competing terms such as prestigious brands with the intent to provide management with tools to the extent to which luxury contributes to a brand, resolve whether or not a brand is a luxury brand, and establish with some accuracy the net worth of the luxury brand market. Chevalier and Manzalovo (2008) propose a restrictive definition of luxury brand, such as "almost the only brand in its product category, giving it the desirable attributes of being scarce, sophisticated and in good taste" (p. viii), which does not make sense in the reality of the consumer. This is true as the description underestimates the unique personalities of the consumer. 
The consumer's direct involvement and notion that a luxury brand is partially built upon the consumer's perceptions help create an image of luxury. Tynan et al. (2010) develop a theoretical framework detailing the types of value for luxury brands and seek to identify processes of value creation. Their research results differentiate luxury brands through creation of a superior value proposition and highlight the number of interactions taking place between luxury brand owners, their customers and members of their respective networks.

It is interesting that in pursuit of a luxury brand definition both consumers and marketers describe luxury products in more abstract language than they describe ordinary products, which abstract product descriptions are perceived as more luxurious than concrete product descriptions (Hansen \& Wänke, 2011). It is said that while consumers in different world regions purchase luxury products for a variety of reasons the characteristics of luxury brand consumers appear to possess similar values regardless of their country of origin. This would help in positioning luxury goods nationally or regionally but would not assist in either an international approach to luxury goods or a move toward a consistent definition.

In sum, different aspects and dimensions need to be considered when defining a luxury brand; these should include: (1) product category, (2) the degree of luxury associated with the brand, and (3) the context of use. While consumers may believe they understand what constitutes a luxury product or brand the concept of luxury appears to be generally similar to the amateur's classic attitude of fine art. "I don't understand art but I know when I see it". It is clear that luxury has unique product, economic and cultural aspects. Adding further complications what may be "luxury" in one culture or region may be a mundane product in another.

\subsection{A New Approach to the Concept of Luxury Brands}

The notion of a consumer brand relationship offers a good base to explain this process of meaning transfer, which is based on the assumption that a brand is a proxy in a dynamic relationship with the customer (Aggarwal 2004; Fournier \& Yao 1996). Grönroos (2001) defines the consumer brand relationship as the sum of experiences that the consumer establishes with a brand. Fournier (1998) states that the consumer brand relationship has legitimacy at the level of consumers' lived experiences and benefits the consumers through the meaning they add to their lives. Aguirre-Rodriguez (2014) discusses how brand personifications are linked to brand images in a cultural context.
Based on the aforementioned literature, the authors in this section propose a new conceptual framework for luxury brands. The luxury product attributes at a basic level may be controlled by the luxury product manager where at the foundation the luxury product delivers a quality offering with high price as well as charming product aesthetics. At an advanced level the luxury product has matured to signal a well-respected, firmly established sign of its luxurious characteristics to the consumer.

\subsubsection{Cognitive Attributes}

The product characteristics of quality, aesthetics and price can be categorized as being the basic building blocks of the consumer's cognitive attributes as they relate to both the product's physical and psychological characteristics. At a basic level in a consumer luxury brand relationship these product characteristics interact with consumer perceptions to form a luxury brand judgment (Saricam et al., 2012).

Quality is considered as a basic component of luxury. Prior research indicates that different brand classifications lead buyers to appraise product quality using different dimensions (Saricam et al., 2012). Consumers often expect higher comparable quality in luxury products and it is unlikely that a luxury image can be sustained without sustaining above average levels of products quality (Christodoulides et al., 2009). Product quality is a cornerstone for rationalizing the purchase of often highpriced luxury brand products (Eastman \& Eastman, 2011). Chung et al. (2014) point out that country of origin plays a large role in a luxury brand's image, understanding the importance of country of origin is vital when attempting to market against foreign competition whose goods may be perceived by the consumer to be of superior quality. It would appear then that product value is not only a function of price and actual quality, but also the perceived quality (Vigneron \& Johnson, 2004). Achabou and Dekhili (2013) support the importance of quality and find that the responsible behavior of a brand remains a secondary selection criterion to a consumer's interest in the intrinsic quality of the product. The cognitive perception of quality is often cited as being more influential than actual quality (Heine \& Phan, 2011), and it is a psychological perception of quality that forms one of the bases of luxury brand image. A constant theme however is that the greater the status of the constructs awarded, the higher the product quality.

Aesthetics are often cited as being a significant factor in the perception of luxury (Townsend \& Sood, 2012). Chitturi et al. (2010) discuss how aesthetic attributes of products relate to brand images. Aesthetic design and ideology are often extensions of highly creative individuals and the aesthetic characteristics they imbue into a product brand 
frequently resemble works of art, inducing emotions of exclusivity and superiority (Dion \& Arnould, 2011). Heine and Phan (2011) provide evidence that product design is a highly valued attribute of luxury products. Dion and Arnould (2011) state that luxury draws on the principles of art and magic to enlist magical and aesthetic principles within or without the store to achieve these ends. Mr. Branchini, a former president of the European Cultural and Creative Industries Alliance and Altagamma, Italy's luxury goods association, states that when the European Union (EU) recognized luxury goods as an industry, the EU's executive body recognized the high-end industry as the pillar of cultural and creative industries (Daneshkhu, 2013). The inherent non-functionality of aesthetics represent a cultural relativity of luxury and can be meaningfully understood in terms of consumer perceptions of aesthetic product features creating a link between high aesthetics and a luxury image.

Price is an important aspect of luxury in the current socioeconomic context; wealth is the only remaining consistent differentiator of social status (Han et al., 2010). To this end, raising the price of a product creates social separation and the image of luxury to those who are unable to afford a product that is beyond their reach. High price is frequently perceived as a differentiator of social status, where conspicuous consumption of luxury is frequently used for the purpose of signaling social status (Eastman \& Eastman, 2011). Price has proven to be the most objective characteristic in evaluating the luxuriousness of a product and requires no psychological perceptions other than one knows the price. Li et al. (2012) examine Chinese consumers' willingness to pay for luxury fashion brands related to their fashion lifestyle and perceived value. Clements and Gao (2012) introduce two related measures based on the luxury-necessity distinction; one is an index of the extent to which the prices of luxuries change as compared to necessities, while the second indexes the change in spending. However, price alone does not create a prestigious image as not all expensive products are considered luxury. Low-priced products are rarely recognized as luxury, so price does establish some form of a fundamental and mandatory expectation level for luxury.

\subsubsection{Extrinsic Attributes}

Consumers use the extrinsic product characteristics of exclusivity and uniqueness as well as the concrete connection with luxuriousness to exhibit social status and association. Han et al. (2010) provide additional insight that the majority of consumers actively signal to others that are equal and above their perceived social status, their personal use and consumption of prominent luxury brands. According to Wilcox et al. (2009), social association and social dissociation reflect consumer aspirational goals where some consumers of perceived higher social status consume luxury in order to dissociate from those of perceived lower status.

An inference that can be made between luxury product characteristics and consumer psychological attributes is that the more rare or more unique a product characteristic is perceived to be, the higher the perceived social value will be and thus the higher price premium and luxuriousness that can be attained. Luxury brand consumers driving social status from the ownership of a rare or unique product can drive price in some sorts of products, such as a treasured painting. Barnier et al. (2015) suggest that there is a luxury continuum at a theoretical level, reinforcing the notions of accessible and prototypical inaccessible luxury. Some would argue these objects have basically limited actual physical product value and only derive additional value from the extrinsic qualities awarded by individuals or groups. As such the value of this classification of products is not related to physical properties but defined as a distinction of perceived social values within a socio-economic context by those that covet them (Vigneron \& Johnson, 2004).

Companies have begun to appreciate the importance of two types of limited edition products. Many luxury brands have begun to launch limited edition products using two types of strategies (Jang et al., 2015). These have particularly popular with Internet marketing and take the form of limited-time scarcity and limited-quantity scarcity messages. Aggarwal et al. (2011) offer that scarcity messages make consumers believe that products limited in availability are more special, unique and valuable. Exclusivity, when defined as limited availability, has two forms: concrete and virtual. Concrete exclusivity relates to physical limitations on production capacity, creating value for those consumers having access to somewhat scarce products (Heine \& Phan, 2011). Virtual exclusivity is a state where firms or distribution channels use selective distribution and marketing strategies to create value through limited accessibility which can be artificially manipulated (Kapferer, 2012). The notion that luxury products are actually becoming more available highlights that these firms have enacted virtual exclusivity tactics to construct themselves as art and adopt a fashion business model while deemphasizing exceptional quality and country of origins.

Uniqueness is a product characteristic that is derived from qualities of distinctive design or construction that can be either functional or trivial. Almost limited to the image of luxury the perception of exclusivity enhances the desirability of a product or brand and therefore participates in consumption (Heine \& Phan, 2011). In an investigation of luxury consumption among Chinese middle-class consumers, Zhan and He (2012) claim that consumers' attitude toward luxury brands broadly depends on consumer 
experience, as luxury products become exposed to consumers as they become less unique.

\subsubsection{Intrinsic Attributes}

Intrinsic product characteristics exist at a higher level of sophistication and include a complex integration of concrete attributes. Symbolic is a characteristic of a luxury product, while consumer psychological characteristics are related to the consumer's perception of how the brand relates to one's self-image. Saenger et al. (2013) discuss how luxury consumption and word-of-mouth communication relates to self-image expressed. Isaksen and Roper (2012) discuss how self-esteem is associated with consumers' consumption attitudes. Kapferer (2012) presents an interesting argument; what luxury sector firms are selling is actually symbolic and a magical power to the masses. Symbolic is a significant characteristic and refers to human values and lifestyles that exceed functional benefits (Heine \& Phan, 2011). Symbolic can be considered as the spiritualization of a product that embodies iconic and in temporal ideologies with little emphasis on the physical form (Dion \& Arnound, 2011). Luxury products often have a war chest of subtle symbolic attributes, immortalized through public displays of superiority, but discreetly embedded within luxury product attributes (Kapferer, 2012).

A similar product characteristic with more concrete basis is heritage. Heritage encompasses attributes, such as country of origin, historical foundation (Kapferer, 2012) and authenticity (Alexander, 2009). A prestigious heritage is constructed and sustained through time and culture by products and brands that are imbedded with historic notions of luxury (Alexander, 2009). Brands possessing heritage characteristics are often perceived as being of superior quality, uniqueness and authentic as a result of their association (Dion \& Arnould, 2011). Consumers' appreciation of a product's symbolic characteristic or heritage drives intrinsic perceptions of the self, which may result in increased perceptions of an owner's value by the owner him/herself or others. Consumers who have the financial ability seek products with sophisticated symbolic features and prestigious heritage. Consumer psychological characteristics of self-esteem (Truong et al., 2010) and selfaffirmation (Townsend \& Sood, 2012) are tied with these product characteristics because they induce an inward valuation of one's identity and worth. Wang et al. (2011) report the more a consumer purchases luxury for selfactualization, the more likely they perceive themselves belonging to an elitist group. Luxury products laden with subtle symbol and heritage can be related to emotional qualities of personal indulgence and self-expression (Eastman \& Eastman, 2011). Due to the transcendence of these intrinsic characteristics from functionality and social pursuits, the value attributable to symbol and heritage defy traditional means of price valuation. As a result, their intrinsic value is driven to be significantly greater than the sum of their cognitive and extrinsic characteristics.

\section{Research Methods}

\subsection{A New Conceptual Framework for Consumer Luxury Brand Relationships}

The luxury product characteristics can be considered as a varying range of dimensions that increase proportionately with perceived luxuriousness. The consumer psychological characteristics are derived from consumers' perception of a luxury product in hierarchical order of: (1) on a basic level, consumers develop a perception of quality, which is combined with the aesthetics and price of a luxury product, likely inducing satisfaction; (2) on a secondary level, consumers use luxury products as an extrinsic signal of higher social status and association with specific social groups, which the consumers likely rely upon exclusivity and uniqueness of the product to create prestige to the brand; and (3) on the highest level, the consumers using luxury products become more intrinsic and spiritual, which the product is likely associated with increasing symbolic features for the consumer's self-image and self-identification As luxury products represent higher degrees of desirable attributes, consumers express higher levels of psychological bonds such as commitment, loyalty and intimacy toward the luxury product or brand.

The authors propose a new consumer luxury brand relationship framework to display how luxury product characteristics are related to consumer psychological characteristics in hierarchical order of values. In extending the highlighted literature the authors propose the following hypotheses:

Hypothesis 1: Cognitive attributes of the luxury product are likely related to consumer psychological bonds toward the brand.

Hypothesis 2: Extrinsic attributes of the luxury product are likely related to consumer psychological bonds toward the brand.

Hypothesis 3: Intrinsic attributes of the luxury product are likely related to consumer psychological bonds toward the brand.

\subsection{Surveys and Sample Characteristics}

Given that the author model embeds complex relationships between luxury product characteristics and 
consumer psychological characteristics and their association with the luxury brand, the study collected selfreported consumer experience and perceptions of the luxury brand. The 25 survey items of measuring luxury product attributes and consumer psychosocial characteristics to the luxury product (brand) were developed from the relationship ideals scale of Fletcher et al. (1999). To collect information about consumer luxury brand relationships, the relationship strength indicators of Aaker et al. (2004) were used.

The first survey was conducted in Lisbon and Porto, Portugal in 2009 for 13 well known luxury brands: Mercedes, BMW, Audi, Chanel, Christian Dior, Gucci, Burberry, Calvin Klein, Hugo Boss, Armani, Ray Ban, Moet et Chandon, and Ralf Lauren. The selection of these brands was judged by the authors from the Leading Luxury Brands 2008 (Interbrand 2008). The samples were selected from the population in some non-random manner by surveyors (the author university research assistants) at department stores, premium outlets and shopping malls in the city. In total 236 consumers responded to the survey. Of 236 respondents 59 surveys were removed from the data set as they had missing data or incomplete information so that resulted in a sample of 177 cases. The sample represents in gender as $47.7 \%$ of male and $52.3 \%$ of female. The mode age of the sample was 30 s (average $=34$, standard deviation $=14.032$ ) with a minimum of 18 and a maximum of 59 years old (see Table 1).

The second survey was conducted in Boston, the United States of America in 2013 for the same 13 well known luxury brands used in the 2009 survey. The selection of these brands was judged by the authors from the Best Global Brands 2013 (Interbrand 2013). The samples were selected from the population in some non-random manner by surveyors (the author university research assistants) at the author's university. In total 232 consumers responded to the survey. Of 232 respondents 38 surveys were removed from the data set as they had missing data or incomplete information so that resulted in a sample of 194 cases. The sample represents in gender as $38.2 \%$ of male and $61.8 \%$ of female. The mode age of the sample was 20s (average = 26 , standard deviation $=6.032$ ) with a minimum of 21 and a maximum of 52 years old. Unlike the 2009 survey respondents the 2013 survey respondents are university students (mostly graduate students) and staff (see Table 1).

\subsection{Factor Analysis and Internal Consistency Reliability Test}

The first exploratory factor analysis uncovers the underlying structure of a large set of items and identifies five components based on an eigenvalue cut-off of one. This resulted in the retention of 19 items out of 25 . The second exploratory factor analysis identifies three components based on an eigenvalue cut-off of one. This resulted in the retention of 14 items out of 18 . To test the appropriateness of factor analysis, two measures - the Kaiser-Meyer-Olkin and the Bartlett's test - were used. The Kaiser-Meyer-Olkin overall measure of sampling adequacy of .887 falls within the acceptable significant level at $p<.001$. The Bartlett's test of sphericity of 4575.602 with 171 degree of freedom shows a highly significant correlation among the survey items at $p<.001$. The sums of squared loadings from the five components have the cumulative value of $73.122 \%$ in explaining the total variance of the data. The results of exploratory factor analysis using principal component analysis extraction method are reported in Table 2.

Table 1. Descriptive Statistics of Brand Experience of the Respondents

\begin{tabular}{|c|c|c|c|c|}
\hline & 2009 Sample (n=177) & 2013 Sample (n=194) & Total $(\mathbf{n = 3 8 1 )}$ & Total $(\mathbf{n = 3 8 1 )}$ \\
\hline Brand Name & Percent (\%) & Percent (\%) & Percent (\%) & Frequency \\
\hline Mercedes & 15.7 & 17.6 & 16.6 & 63 \\
\hline BMW & 11.0 & 13.2 & 12.1 & 47 \\
\hline Audi & 5.6 & 4.1 & 4.8 & 18 \\
\hline Chanel & 11.5 & 12.0 & 11.7 & 45 \\
\hline Christian Dior & 9.9 & 11.1 & 10.5 & 40 \\
\hline Gucci & 10.0 & 9.0 & 9.5 & 36 \\
\hline Burberry & 11.3 & 9.2 & 10.1 & 38 \\
\hline Calvin Klein & 6.8 & 8.3 & 7.5 & 29 \\
\hline Hugo Boss & 7.9 & 5.1 & 6.5 & 25 \\
\hline Armani & 4.5 & 5.2 & 4.8 & 18 \\
\hline Ray Ban & 3.4 & 2.1 & 2.7 & 10 \\
\hline Moet et Chandon & 1.1 & 2.1 & 1.6 & 6 \\
\hline Ralf Lauren & 2.3 & 1.0 & 1.6 & \\
\hline Total & 100 & 100 & 100 & 6 \\
\hline
\end{tabular}


Internal consistency reliability is a measure of how well a test addresses different constructs and delivers reliable scores. The most common method for assessing internal consistency is Cronbach's alpha. This form of intra-class correlation is closely related to convergent validity, i.e. the extent to which the items in a scale are all highly intercorrelated. The test also takes into account both the size of the sample and the number of potential responses. The Cronbach's alpha test is preferred in this study due to the benefit of averaging the correlation between every possible combination of split halves and allowing multi-level responses. The detailed results of internal consistency reliability tests, including item-total correlation coefficient values, are reported in Table 2.

Table 2. Results of Factor Analysis

\begin{tabular}{|c|c|c|c|c|c|c|}
\hline Construct names & Question items & $\begin{array}{c}\text { Factor } \\
\text { loadings }\end{array}$ & Eigenvalues & $\begin{array}{c}\% \text { of } \\
\text { variance }\end{array}$ & $\begin{array}{c}\text { Cronbach } \\
\alpha\end{array}$ & $\begin{array}{l}\text { Item-total } \\
\text { correlation }\end{array}$ \\
\hline \multirow[t]{4}{*}{ Commitment } & BA2 & .633 & 2.489 & 13.101 & .794 & .669 \\
\hline & BA3 & .827 & & & & .615 \\
\hline & BA4 & .551 & & & & .486 \\
\hline & BA6 & .686 & & & & .651 \\
\hline \multirow[t]{3}{*}{ Loyalty } & BA9 & .624 & 2.456 & 12.927 & .865 & .622 \\
\hline & BA10 & .893 & & & & .836 \\
\hline & BA11 & .877 & & & & .764 \\
\hline \multirow[t]{2}{*}{ Satisfaction } & BA13 & .723 & 1.722 & 9.061 & .721 & .564 \\
\hline & BA14 & .622 & & & & .564 \\
\hline \multirow[t]{5}{*}{ Intimacy } & BA15 & .714 & 3.761 & 19.794 & .895 & .746 \\
\hline & BA16 & .678 & & & & .737 \\
\hline & BA17 & .807 & & & & .778 \\
\hline & BA18 & .801 & & & & .716 \\
\hline & BA19 & .779 & & & & .730 \\
\hline \multirow[t]{5}{*}{ Prestige } & BA21 & .756 & 3.465 & 18.239 & .886 & .714 \\
\hline & BA22 & .828 & & & & .754 \\
\hline & BA23 & .848 & & & & .797 \\
\hline & BA24 & .784 & & & & .739 \\
\hline & BA25 & .721 & & & & .617 \\
\hline \multirow[t]{5}{*}{ Cognitive attributes } & CA1 & .782 & 3.386 & 18.808 & .819 & .660 \\
\hline & CA2 & .751 & & & & .627 \\
\hline & CA3 & .737 & & & & .584 \\
\hline & CA4 & .714 & & & & .582 \\
\hline & CA5 & .715 & & & & .575 \\
\hline \multirow[t]{5}{*}{ Intrinsic attributes } & CA6 & .637 & 2.893 & 16.069 & .820 & .662 \\
\hline & CA7 & .742 & & & & .754 \\
\hline & CA8 & .739 & & & & .508 \\
\hline & CA9 & .696 & & & & .517 \\
\hline & CA10 & .729 & & & & .629 \\
\hline \multirow[t]{4}{*}{ Extrinsic attributes } & CA15 & .744 & 2.542 & 14.121 & .756 & .532 \\
\hline & CA16 & .719 & & & & .500 \\
\hline & CA17 & .813 & & & & .555 \\
\hline & CA18 & .771 & & & & .624 \\
\hline
\end{tabular}




\subsection{Structural Equation Model and Estimates}

The analysis of moment structures was used for an empirical test of the structural model. The maximum likelihood estimation was applied to estimate numerical values for the components in the model. When comparing non-nested models, the Akaike information criterion fit index is used as our first choice because the difference in the Chisquare values among the models cannot be interpreted as a test statistic (Kline, 2005), the root mean square of approximation fit index as the second choice and then the goodness of fit index as the third. The results of the analysis of moment structures generally achieve acceptable goodness-of-fit measures (see Table 3 ). For example, the index of the goodness of fit index $(=.928)$ indicates that the fit of the proposed model is about $93 \%$ of the saturated model (the perfectly fitting model). The index of the normed fit index $(=.913)$ indicates that the fit for the proposed model is about $91 \%$.

In testing hypothesis 1 that the cognitive attributes of the luxury product are likely related to consumer psychological bonds to the brand, Table 3 shows that there are positive relationships between the latent variables and it is statistically significant at a $99 \%$ confidence level $(p<.01)$. In testing hypothesis 2 that the extrinsic attributes of the luxury product are likely related to consumer psychological bonds to the brand, Table 3 shows that there are positive relationships between the latent variables and it is statistically significant at a $99 \%$ confidence level $(p<.01)$. In testing hypothesis 3 that the intrinsic attributes of the luxury product are likely related to consumer psychological bonds to the brand, Table 3 shows that there are positive relationships between the latent variables and it is also statistically significant at a $99 \%$ confidence level $(p<.01)$.

\section{Results and Discussion}

The authors provide a definition of luxury brands through the viewpoint of: (1) the luxury product characteristics, (2) the consumer psychological characteristics toward the luxury product, and (3) the consumer personal relationship to the product (brand), which acts as a link binding the individual's personality dimensions to the physical and psychological brand attributes. In providing the BECKER luxury brand model there appears to be three important developmental stages in what one might consider a pyramid structure that has a broad and strong solid foundation, which other luxury brand characteristics are built upon. The BECKER luxury brand model illustrates how the luxury product characteristics combine with the consumer psychological characteristics to create the consumer luxury

Table 3. Results of Structural Equation Model Estimates

\begin{tabular}{|c|c|c|c|c|c|}
\hline Нypo. & Path & $\begin{array}{l}\text { 2009Sample } \\
(n=177)\end{array}$ & $\begin{array}{c}\text { 2013Sample }(n=1 \\
94)\end{array}$ & Total $\quad(n=381)$ & Decision \\
\hline \multirow[t]{5}{*}{$\mathrm{H} 1$} & Cognitive $\rightarrow$ Commitment & $.266^{\star * *}$ & $.289^{* * *}$ & $.306^{* * *}$ & Accept \\
\hline & $\rightarrow$ Loyalty & $.264^{\star * *}$ & $.321^{* * *}$ & $.303^{* * *}$ & Accept \\
\hline & $\rightarrow$ Intimacy & $.306^{\star \star *}$ & $.393^{\star * *}$ & $.395^{\star * *}$ & Accept \\
\hline & $\rightarrow$ Prestige & $.327^{\star \star \star}$ & $.371^{\star \star *}$ & $.373^{\star * *}$ & Accept \\
\hline & $\rightarrow$ Satisfaction & $.326^{\star \star \star}$ & $.371^{* \star *}$ & $.393^{\star * *}$ & Accept \\
\hline \multirow[t]{5}{*}{$\mathrm{H} 2$} & Extrinsic $\rightarrow$ Commitment & $.257^{* * *}$ & $.265^{\star * *}$ & $.281^{* * *}$ & Accept \\
\hline & $\rightarrow$ Loyalty & $.311^{* * *}$ & $.367^{* * *}$ & $.378^{* * *}$ & Accept \\
\hline & $\rightarrow$ Intimacy & $.435^{\star * *}$ & $.457^{* * *}$ & $.475^{\star \star \star}$ & Accept \\
\hline & $\rightarrow$ Prestige & $.231^{\star \star \star}$ & $.215^{\star \star \star}$ & $.228^{\star * *}$ & Accept \\
\hline & $\rightarrow$ Satisfaction & $.528^{\star \star \star}$ & $.522^{\star \star \star}$ & $.542^{\star \star *}$ & Accept \\
\hline \multirow[t]{5}{*}{$\mathrm{H} 3$} & Intrinsic $\rightarrow$ Commitment & $.497^{* * *}$ & $.455^{* * *}$ & $.471^{* * *}$ & Accept \\
\hline & $\rightarrow$ Loyalty & $.563^{* * *}$ & $.499^{* * *}$ & $.435^{\star * *}$ & Accept \\
\hline & $\rightarrow$ Intimacy & $.282^{* \star *}$ & $.227^{* \star *}$ & $.351^{* * *}$ & Accept \\
\hline & $\rightarrow$ Prestige & $.571^{\star \star *}$ & $.439^{\star \star \star *}$ & $.465^{\star * *}$ & Accept \\
\hline & $\rightarrow$ Satisfaction & $.497^{* * *}$ & $.462^{\star \star *}$ & $.488^{\star * *}$ & Accept \\
\hline
\end{tabular}

Note: Numbers in the cells are standardized regression weights.

Probability values for rejection of the null hypothesis of zero coefficient are employed at the .05 level $\left({ }^{* * *} p<.01\right)$.

Model fit summary: $X^{2}=869.782$, degree of freedom $=616$

Model fit measures: GFI (= .928), AGFI (= .903), PGFI $(=.895), \operatorname{RMR}(=.043)$.

Baseline comparisons measures: NFI (= .913), RFI (= .903), TLI (= .935), CFI (= .942).

Parsimony-adjusted measures: PRATIO (= .925), PNFI (= .872), PCFI $(=.895)$.

RMSEA $(=.036)$, the Akaike information criterion, AIC $(=3258.948)$. 


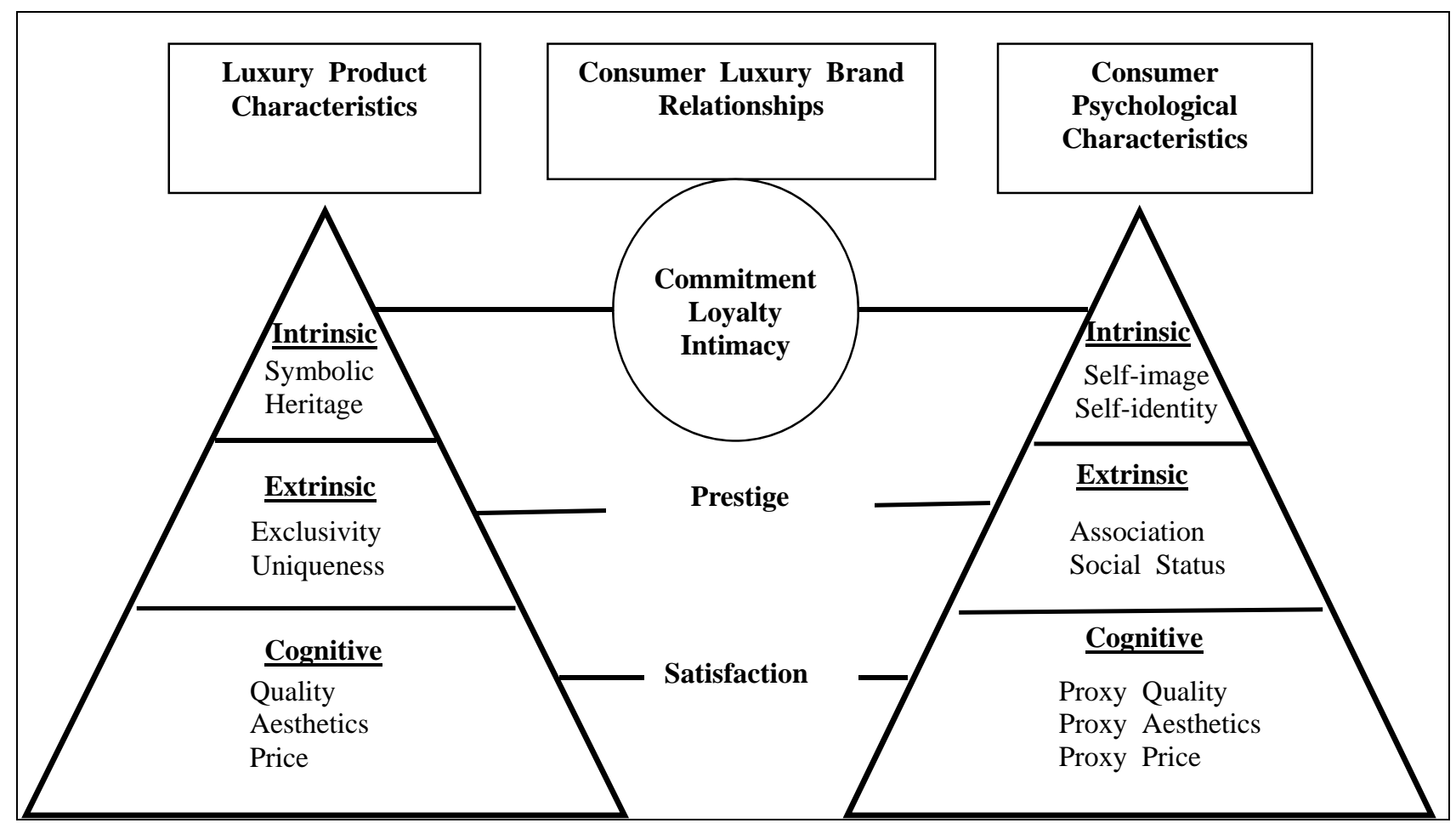

Figure 1. The BECKER Model of Consumer Luxury Brand Relationships

brand relationship. The BECKER framework also describes how these aspects of the relationship interrelate in hierarchical order of values (see Figure 1). The BECKER luxury brand model defines three main categories of the consumer luxury brand relationship, each exploring how the consumer has developed a specific aspect of the consumer luxury brand relationship around a set of relationship variables.

At its base level, the consumer psychological characteristics require a firm understanding and assurance of a luxury product's high quality. Generally quality of a luxury product can be derived from the product's image and/or aesthetic value to a greater extent than the product's actual quality. It is at this point that marketing plays a significant and decisive role. Consumer psychological characteristics are derived from the consumer perceptions of the luxury product physical characteristics and for a basic level consumers develop a perception of the quality that is combined with the aesthetics of a product, inducing satisfaction. Satisfaction indicates evaluations of the attributes and happiness in the relationship. Consumers make inferences through the observation of a brand's behaviors. The sum of these inferences will form a global evaluation that the customer develops into the brand and its role as a proxy in the relationship. Proxy-quality inferences are nurtured in judgments of equity and justice in socioemotional benefits and have the purpose of calibrating the belief the customer has in the relationship with the brand. This includes aspects of dependability, reliability, trust and accountability. The proxy-quality includes items that focus on aspects of trust and trustworthiness and include perceived reliability and dependability (Aaker et al., 2004) as well as transgression commission.

On a secondary level, consumers use luxury products as an extrinsic signal of higher social status and association with specific social groups of consumers, relying upon the exclusivity and extraordinary physical characteristics to create a self-connection. Self-connection is defined as deep and strong ties created by actions that evoke the individual's identity system. At this stage the consumer enjoys belonging to a premium social status, seeking a positive perception from other by being part of a very selective group possession the luxury product. The consumer is also an active player in defining the group, developing a sense of self-identification and togetherness to the luxury brand. Shukla (2011) provides insights into how interpersonal influences and branding cues shape consumer luxury purchase intentions. The study found that British consumers relied increasingly on branding cues and also that brand image was found to be a significant moderator between 
normative interpersonal influences and luxury purchase intentions in India and England. Simonson and Rosen (2014) note that luxury goods appeal to buyers' emotions rather than their senses so that "reviews aren't a big factor" (p. 25). The membership in the brand is developed such that consumers relate to the brand and to each other with less interest in the wisdom of outsider's opinions.

At the advance level, consumer psychological characteristics become more intrinsic and spiritual, which correlates with increasing symbolic in physical characteristics. As luxury products exhibit higher degrees of desirable physical characteristics, the brand embodies higher levels of psychological value to consumers. Together they create a consumer luxury brand bond that suggests a stronger consumer luxury brand relationship. It is the interaction with the consumer unique personality dimensions that are attributed to creating magic or intimacy behind the luxury brand image. It is the glue binding the individual uniquely to the product's physical and psychological characteristics and thus creating its distinctive personal values. At this relatively rare stage, the feeling toward the brand is matured to the point where the consumer perceived a total sense of natural righteousness to be a regular and special client of the luxury brand. Commitment is the instrumental nature of the construct that measures the investments in the relationship to make it enduring in the behavior conducive to loyalty. Intimacy implies that the brand knows the customer and is able to create an atmosphere that encourages the costumer to share personal information with it. It is measured by the perceived depth of the brand's understanding of the consumers and vice-versa by the consumers' understanding of the brand, and the consumers' willingness to share personal information (Aaker et al., 2004).

\section{Implication for Managerial Actions}

The authors propose the BECKER luxury brand model (see Figure 1) that delineates the attributes that provide a definition of the luxury product and underscores the complexity of attempting to develop a definition by addressing the luxury product physical and psychological characteristics. The BECKER model of consumer luxury brand relationships displays that this relationship is sophisticated in nature and the result of a series of complex brand personality interactions. The BECKER model suggests that the consumer luxury brand relationship can be successfully maintained, while needing to be adapting to life and company changes. A company must be diligent that both the consumer's and the brand's personality remain in equilibrium over time through by carefully manipulating the author luxury brand model attributes.

The successful application of an interpersonal relationship inventory in a branding setting would be of particular interest to marketers and provides a basic and user-friendly framework that is useful in the development of a brand strategy. As high price and quality were expectations of luxury goods it would be difficult to reduce either during periods of economic down turns. When considering then what the author model offers to management knowledge it would be important to note that:

- The factors of model importance and how these individually, or collectively, relate to brand sustainability.

- That luxury brand development is a complex organization of individual characteristics.

- Those characteristics are organized into the categories of physical and psychological and that each division contains important individual traits. Marketers must consider the balance between the two as each contributes a unique aspect in both sales and sustainability of the brand.

- Marketers when considering a brand strategy must consider each of the distinct divisions and determine weights to award to the individual division traits when developing the overall strategy.

- This study emphasizes the role of the consumer luxury brand relationship in appreciating and defining luxury brand symbolic consumption.

It is said that even downturns in business cycles present opportunities for firms to capture shifting loyal and non-loyal consumers from competitors. This would seem true in the luxury sector as well; the authors recommend that companies seize such opportunities to redirect shifters toward their product choices. To the best of our knowledge, surprisingly little research has addressed some important issues for luxury brands in comparison to non-luxury brands. An understanding of the characteristics of the luxury brand definition that correlate to their own product and their competitor's product would assist in understanding how to direct such efforts. An older perspective holds that loyal consumers are costly to redirect, however, it is possible that through a broader understanding of the luxury constructs underlying the consumer luxury brand relationship repositioning even the most loyal consumer may be highly feasible.

By offering a multi-dimensional approach the BECKER luxury brand model offers a more holistic perspective in the understanding of the constructs of luxury brand personality. One substantial contribution of the study is to promote the understanding of how the consumer luxury brand relationship such as commitment and loyalty can stimulate sales, and a relationship such as intimacy can contribute to 
business continuity during times of brand disruptions. This is directly relevant to how a firm should position the luxury brand's consumer relationship with the understanding the factors such as commitment and loyalty, which may have immediate sales consequences and may be able to sustain the consumer's bond should disruptions occur in the manner that products positioned around aspects of brand intimacy might.

\section{Conclusions}

The paper illustrates the role of the consumer luxury brand relationship in appreciating and defining multi-brand symbolic consumption. The paper proposes a new framework, the BECKER luxury brand model, from a perspective of marketers and from the dimensions of: (1) the luxury product characteristics, (2) the consumer's psychological characteristics, and (3) the consumer's psychological association with the luxury product. The link between luxury product and the consumer's psychological association provides in hierarchical order of cognitive characteristics at its base level, extrinsic characteristics on a secondary level, and intrinsic characteristics at an advance level. In conclusion, the paper provides a more holistic perspective in the understanding of the constructs of luxury brand personality and consumer luxury brand relationships.

However, the research was conducted in Portugal and the United States so that there is always a potential criticism concerning the ability to generalize research results to a broader international population.

\section{References}

Aaker, J., Fournier, S., \& Brasel, A. (2004). When good brands do bad. Journal of Consumer Research, 31(1), 1-16.

Achabou, M. K., \& Dekhili, S. (2013). Luxury and sustainable development: Is there a match?. Journal of Business Research, 66(10), 1896-1903.

Aggarwal, P. (2004). The effects of brand relationship norms on consumer attitudes and behavior. Journal of Consumer Research, 31(1), 87-101.

Aggarwal, P., Jun, S. Y., \& Huh, J. H. (2011). Scarcity messages: A consumer competition perspective. Journal of Advertising, 40(3), 19-30.

Aguirre-Rodriguez, A. (2014). Cultural factors that impact brand personification strategy effectiveness. Psychology \& Marketing, 31(1), 70-83.

Alexander, N. (2009). Brand authentication: Creating and maintaining brand auras. European Journal of $M$ arketing, 43(3/4), 551-562.

Al-Mutawa, F. S. (2013). Consumer-generated representations: Muslim women recreating western luxury fashion brand meaning through consumption. Psychology \& Marketing, 30(3), 236-246.

Barnier, V., Falcy, S., \& Valette-Florence, P. (2012). Do consumers perceive three levels of luxury? A comparison of accessible, intermediate and inaccessible luxury brands. Journal of Brand Management, 19(7), 623-636.

Becker, K., \& Nobre, H. M. (2013). Brand personality as a predictor in the product/firm relationship as it relates to brand loyalty during periods of brand stress, catastrophic events or recalls. Journal for Global Business Advancement, 6(3), 212-225.

Chevalier, M., \& Mazzalovo, G. (2008). Luxury Brand Management, Singapore: Wiley

Chitturi, R., Chitturi, P., \& Raghavarao, D. (2010). Design for synergy with brand or price information. Psychology \& Marketing, 27(7), 679-697.

Christodoulides, G., Michaelidou, N., \& Li, C. H. (2009). Measuring perceived brand luxury: An evaluation of the BLI scale. Journal of Brand Management, 16(5/6), 395-405.

Chung, K., Youn, C., \& Lee, Y. (2014). The influence of luxury brands' cross-border acquisition on consumer brand perception. Clothing and Textiles Research Journal, 32(4), 219-234.

Clements, K. W., \& Gao, G. (2012). Quality, quantity, spending and prices. European Economic Review, 56(7), 1376-1391

Daneshkhu, S. (2013). Strategic industry comes of age. Financial Times Special Report, June 2. Retrieved November 23, 2016, from http://www.ft.com/intl/cms/s/0/a25f51f0-b70c-11e2a249-00144feabdc0.html\#axzz3CqRv0Ewf

Dion, D., \& Arnould, E. (2011). Retail luxury strategy: Assembling charisma through art and magic. Journal of Retailing, 87(4), 502-520.

Eastman, J. K., \& Eastman, K. L. (2011). Perceptions of status consumption and the economy. Journal of Business and Economics Research, 9(7), 9-20.

Fletcher, G. J. O., Simpson, J. A., Thomas, G., \& Giles, L. (1999). Ideals in intimate relationships. Journal of Personality and Social Psychology, 76(1), 72-89.

Fournier, S. (1998). Consumers and their brands: Developing relationship theory in consumer research. Journal of Consumer Research, 24(4), 343-353.

Fournier, S., \& Yao, J. L. (1996). Reviving brand loyalty: A reconceptualization within the framework of 
consumer-brand relationships. Working paper, Harvard Business School, Cambridge, MA.

Grönroos, C. (2001). Service Management and Marketing: A customer relationship management approach (2nd ed.). West Sussex, UK: Wiley

Han, Y. J., Nunes, J. C., \& Dreze, X. (2010). Signaling status with luxury goods: The role of brand prominence. Journal of Marketing, 74(4), 15-30.

Hansen, J., \& Wänke, M. (2011). The abstractness of luxury. Journal of Economic Psychology, 32(5), 789-796.

Heine, K., \& Phan, M. (2011). Trading-up mass-market goods to luxury products. Australasian Marketing Journal, 19(2), 108-114.

Interbrand (2008). The leading luxury brands 2008. Retrieved September 9, 2009 from http://www.interbrand.com/Libraries/Branding_Studie s/The_Leading_Luxury_Brands_2008.sflb.ashx

Interbrand (2013). The best global brands 2013. Retrieved March 23, 2013 from http://interbrand.com/bestbrands/best-global-rands/2013/ranking/ \#?filter=Luxury\&listFormat=ls

Isaksen, K. J., \& Roper, S. (2012). The commodification of self-esteem: Branding and British teenagers. Psychology \& Marketing, 29(3), 117-135.

Jang, W. E., Ko, Y. J., Morris, J. D., \& Chang, Y. (2015). Scarcity message effects on consumption behavior: Limited edition product considerations. Psychology \& Marketing, 32(10), 989-1001.

Kapferer, J. N. (2012). Abundant rarity: The key to luxury growth. Business Horizons, 55(5), 453-462.

Kline, R. B. (2005). Principles and practices of structural equation modeling (2nd ed.). New York, NY: Guilford Press

Ko, E., \& Megehee, C. M. (2012). Fashion marketing of luxury brands: Recent research issues and contributions. Journal of Business Research, 65(10), 1395-1398

Lee, E. J. (2013). A prototype of multicomponent brand personality structure: A consumption symbolism approach. Psychology \& Marketing, 30(2), 173-186.

Lee, M., Ko, E., Lee, S., \& Kim, K. (2015). Understanding luxury disposition. Psychology \& Marketing, 32(4), 467-480.

Li, G., Li, G., \& Kambele, Z. (2012). Luxury fashion brand consumers in China: Perceived value, fashion lifestyle, and willingness to pay. Journal of Business Research, 65(10), 1516-1522.

Liao, J., \& Wang, L. (2009). Face as a mediator of the relationship between material value and brand consciousness. Psychology \& Marketing, 26(11), 987-1001.
Miller, K. W., \& Mills, M. K. (2012). Contributing clarity by examining brand luxury in the fashion market. Journal of Business Research, 65(10), 1471-1479.

Okonkwo, U. (2009). The luxury brand strategy challenge. Journal of Brand Management, 16(5/6), 287-289.

Reyneke, M., Sorokácová, A., \& Pitt, L. (2012). Managing brands in times of economic downturn: How do luxury brands fare?. Journal of Brand Management 19(6), 457-466.

Riley, F. D., Lomax, W., \& Blunden, A. (2004). Dove vs. Dior: Extending the brand extension decision-making process from mass to luxury. Australasian Marketing Journal, 12(3), 40-55.

Saenger, C., Thomas, V. L., \& Johnson, J. W. (2013). Consumption-focused self-expression word of mouth A new scale and its role in consumer research. Psychology \& Marketing, 30(11), 959-970.

Saricam, C., Aksoy, A., \& Kalaoglu, F. (2012). Determination of the priorities of customer requirements and quality in apparel retail industry. International Journal of Business and Social Science, 3(16), 242-250.

Shukla, P. (2011). Impact of interpersonal influences, brand origin and brand image on luxury purchase intentions: Measuring interfunctional interactions and a crossnational comparison. Journal of World Business, 46(2), 242-252.

Simonson, I., \& Rosen, E. (2014). What marketers misunderstand about online reviews. Harvard Business Review, January-February, 23-25

Sung, Y., Choi, S. M., Ahn, H., \& Song, Y. A. (2015). Dimensions of luxury brand personality: Scale development and validation. Psychology \& Marketing, 32(1), 121-132.

Townsend, C., \& Sood, S. (2012). Self-affirmation through the choice of highly aesthetic products. Journal of Consumer Research, 39(2), 415-428.

Truong, Y., McColl, R., \& Kitchen, P. J. (2010). Uncovering the relationships between aspirations and luxury brand preference. Journal of Product and Brand Management, 19(5), 346-355.

Tynan, C., McKechnie, S., \& Chhuon, C. (2010). Cocreating value for luxury brands. Journal of Business Research, 63(11), 1156-1163.

Vigneron, F., \& Johnson, L. W. (2004). Measuring perceptions of brand luxury. Journal of Brand Management, 11(6), 484-506.

Wang, Y., Sun, S., \& Song, Y. (2011). Chinese luxury consumers: Motivation, attitude and behavior. Journal of Promotion Management, 17(3), 345-359. 
Wiedmann, K. P., Hennigs, N., \& Siebels, A. (2009). Valuebased segmentation of luxury consumption behavior. Psychology \& Marketing, 26(7), 625-651.

Wilcox, K., Kim, H. M., \& Sen, S. (2009). Why do consumers buy counterfeit luxury brands?. Journal of Marketing Research, 46(2), 247-259.

Wong, N. Y., \& Ahuvia, A. C. (1998). Personal taste and family face: Luxury consumption in Confucian and western societies. Psychology \& Marketing, 15(5), 423-441.

Zhan, L., \& He, Y. (2012). Understanding luxury consumption in China: Consumer perceptions of best-known brands. Journal of Business Research, 65(10), 1452-1460. 